\title{
Factors associated with Hepatitis B screening and completion of vaccination schedule among young psychoactive substance users in Kampala's informal settlements, Uganda
}

\section{Tonny Ssekamatte ( $\sim$ ssekamattet.toca@gmail.com )}

Makerere University School of Public Health https://orcid.org/0000-0002-8127-6759

John Bosco Isunju

Makerere University School of Public Health

Joan Nankya Mutyoba

Makerere University School of Public Health

Moses Tetui

Makerere University School of Public Health

Richard K. Mugambe

Makerere University School of Public Health

\section{Aisha Nalugya}

Makerere University School of Public Health

\section{Brenda Wagaba}

Makerere University School of Public Health

\section{Patience Oputan}

Makerere University School of Social Sciences

Justine Nnakate Bukenya

Makerere University School of Public Health

\section{Esther Buregyeya}

Makerere University School of Public Health

Simon P.S. Kibira

Makerere University School of Public Health

\section{Research article}

Keywords: Hepatitis B, young people, vaccination, informal settlements, screening, Kampala, Urban

Posted Date: March 3rd, 2020

DOI: https://doi.org/10.21203/rs.3.rs-15918/v1 
License: (c) (i) This work is licensed under a Creative Commons Attribution 4.0 International License. Read Full License 


\section{Abstract}

Background Young psychoactive substance users exhibit high-risk behaviours which can increase their risk to Hepatitis $B$ infection. However, there is limited information on screening, and completion of the Hepatitis $B$ vaccination schedule among young psychoactive substance users in informal settlements. Therefore, this study determined the factors associated with Hepatitis B screening, and completion of the Hepatitis B vaccination schedule among young psychoactive substance users in Kampala's informal settlements, Uganda.

Methods A cross-sectional study design was used. Respondent driven sampling was used to enroll 768 respondents from 12 informal settlements. Data were collected using a structured questionnaire and analysed using Stata version 14. A "modified" Poisson regression analysis was done to determine the factors associated with Hepatitis B screening while logistic regression was used to determine the factors associated with completion of the Hepatitis $B$ vaccination schedule.

Results Out of the 768 respondents, only $13.3 \%$ had ever screened for Hepatitis B and $2.7 \%$ had completed the Hepatitis B vaccine schedule. Being a female (aPR 1.61, 95\% Cl: 1.11-2.33), earning a monthly income >USD 136 (aPR 1.78, 95\% Cl: 1.11-2.86); completion of the Hepatitis B vaccination schedule (aPR 1.85, 95\% Cl: 1.26-2.70); lack of awareness about the recommended Hepatitis $\mathrm{B}$ vaccine dose (aPR 0.43, 95\% Cl: 0.27-0.68); and the belief that the Hepatitis $B$ vaccine is effective in preventing Hepatitis B infection (aPR 3.67, 95\% Cl: 2.34-5.73) were associated with "ever screening" for Hepatitis B. Knowledge about the recommended Hepatitis B vaccine dose (aOR 0.06, 95\% Cl: 0.01-0.35); "ever screening" for hepatitis B (aOR 9.68, 95\% Cl: 2.17-43.16) and the belief that the hepatitis B vaccine is effective in preventing Hepatitis B infection (aOR 11.8, 95\% Cl: 1.13-110.14) were associated with completion of the Hepatitis $B$ vaccination schedule.

Conclusion Our findings indicate a low prevalence of Hepatitis B screening and completion of the Hepatitis $B$ vaccination schedule among young psychoactive substance users in informal urban settings. It is evident that lack of awareness about Hepatitis B is associated with the low screening and vaccination rates. We recommend mass sensitisation of young psychoactive substance users in urban informal settlements on Hepatitis B.

\section{Background}

Globally, the consumption of psychoactive substances is an increasing public health problem. It was estimated that in 2016, 275 million people used psychoactive substances such as cannabis (marijuana), amphetamines, opioids and cocaine. Among these, at least 31 million suffered from drug use disorders (1). The use of psychoactive substances is associated with high risk behaviours such as having multiple sexual partners, unprotected intercourse, drug-sex exchanges and sharing of drug preparation equipment such as used needles (2). These behaviours increase the risk of transmission of Hepatitis B virus (HBV) infection (2). Hepatitis B is a potentially life threatening infection caused by HBV (3). It accounts for over 
780,000 deaths each year (3). Hepatitis B infections are often associated with hepatocellular carcinoma, liver cirrhosis, inflammation and at times death $(4,5)$. These outcomes pose a serious economic burden on both the healthcare system and households (6-8).

Owing to the public health significance of Hepatitis $\mathrm{B}$, the World Health Organisation (WHO) instituted the first guidelines for the prevention, care and treatment of persons living with chronic Hepatitis $B$ infection and guidelines for Hepatitis B testing which emphasized testing for high-risk groups such as psychoactive substance users (5). The aim of these guidelines is to strengthen and expand the existing prevention, care and treatment strategies including Hepatitis $B$ testing and vaccination $(5,9)$. Screening and vaccination are the cornerstone of Hepatitis B prevention. Hepatitis B screening is the gateway for access to both prevention, care and treatment services (9). It presents an opportunity for health education, counselling and provision of prevention commodities such as sterile needles to injecting psychoactive substance users (9). On the other hand, vaccination can reduce the incidence of Hepatitis B infections $(10,11)$.

WHO recommends that high-risk groups such as psychoactive substance users including injection drug users should be tested for and vaccinated with three doses of the recombinant deoxyribonucleic acid or plasma-derived Hepatitis B vaccine (3). Despite the recommendations, Hepatitis B screening and vaccination programs targeting psychoactive substance users are still uncommon especially in informal settings (12). Even where services are available, psychoactive substance users often shy away from these programs due to the costs involved and fear to commit to the vaccination schedule $(12,13)$. Consequently, only a small percentage of individuals with Hepatitis B either know their serostatus or are able to access the treatment, care and support they need (14). The majority often report with the advanced disease (5).

Young psychcoactive substance users (defined as individuals aged 10-24 who use psychoactive substances) in informal settlements are not different. Due to their low socioeconomic status and limited access to healthcare services (15-20), they are more likely to be unaware of their Hepatitis B status, and unvaccinated. Nonetheless, there is still limited evidence on the prevalence and factors associated with Hepatitis B screening and competition of the Hepatitis B vaccination schedule among young psychoactive substance users in informal settlements. Yet, these engage in high-risk sexual behaviours that can potentially increase transmission of blood borne infections including Hepatitis B (21). Understating the predictors of Hepatitis B screening and vaccination among young psychoactive substance users would be an important stride to fulfilling the targets of the global hepatitis response strategy. The strategy specifically targets a $90 \%$ reduction in new cases of chronic Hepatitis infection and $65 \%$ reduction in deaths from chronic hepatitis B by 2021 (22).

This study utilised the Knowledge Attitude and Practice model $(23,24)$ to determine the factors associated with Hepatitis B screening and vaccination among young psychoactive substance users in Kampala's informal settlements, Uganda. This model has also been applied in other Hepatitis B studies to 
understand the factors associated with screening and vaccination status among other high-risk groups (25-27). The information generated by this study can be used to inform Hepatitis B prevention programs.

\section{Materials And Methods Scope and Design}

This cross-sectional study was conducted in the informal settlements of Kampala, the largest urban centre and capital city of Uganda. Kampala's population is estimated at 1.5 million, $27.5 \%$ of whom are aged between 15-24 years (28). The city has five metropolitan administrative divisions -Nakawa, Rubaga, Makindye, Central and Kawempe, and is home to Uganda's national referral hospitals, including Mulago national specialized hospital, Kiruddu hospital, Kawempe hospital and Butabika national mental referral hospital.

\section{Sampling}

The sample size was calculated using the Kish Leslie formula for cross-sectional studies (29). Since there was limited evidence on the prevalence of Hepatitis B screening or completion of the Hepatitis B vaccination schedule among young psychoactive substance users in informal settlements, we chose a conservative prevalence of $50 \%$ (30), a 95\% level of confidence, a margin of error (d) of 0.05 and a design effect of $2.0(30,31)$ was used to determine the sample size. This yielded a sample size of 768 young psychoactive substance users. A total of 12 informal settlements were purposively selected for geographical representation of the informal settlements in the city. The settlements included Kinawataka; Luzira; Luzira-Kirombe; Kitintale, Nalukolongo; Wankulukuku-Kabowa; Kamwokya; Bwaise; Katanga; Katwe-Kinyoro; Namuwongo-Soweto and Kyebando.

After the purposive selection of informal settlements, respondent driven sampling was used in the selection of study participants. For each of the informal settlements, we used community leaders who had participated in a previous study in the informal settlements to identify four individuals who acted as primary seeds (32). At the time of enrolment of primary seeds, research assistants made sure that the selected individuals were not under the influence of psychoactive substances. The selected seeds were first interviewed by research assistants prior to being given coupons to enroll secondary seeds. The secondary seeds were then requested by the primary seeds to report at an agreed venue to be interviewed after providing informed consent. The detailed procedure of undertaking respondent driven sampling is documented by (31).

\section{Eligibility criteria}

Only young psychoactive substance users aged 18 years and above were interviewed. These must have stayed in the informal settlement for at least 6 months. All young psychoactive substance users who were sick or under the influence of psychoactive substances were not interviewed. 


\section{Variable measurement}

The main outcomes of interest in this study were having undergone hepatitis B screening in the last 12 months and completion of the Hepatitis B vaccination schedule based on the WHO recommendation of 3 vaccine doses (33). However, the completion was irrespective of the timing of the vaccinations. Selfreports were used to measure completion of the vaccination schedule.

The independent variables included the respondents' socio-demographic characteristics such as sex, age, history of substance use, level of education, and their knowledge and attitude towards Hepatitis $B$ prevention strategies. Knowledge was assessed using questions on the recommended Hepatitis $B$ vaccine dose and the duration the vaccine protects someone against the Hepatitis $B$ infection. Attitude was measured using a question on the perceived efficacy of Hepatitis B vaccine. History of substance use was classified as "ever used' which referred to lifetime use of a psychoactive substance; 'recent use' which referred to having used a psychoactive substance in the last 12 months and 'current use' referring to the use of a psychoactive substance in the last 30 days.

\section{Data management and analysis}

A structured questionnaire was designed using the kobo tool box online platform and later preloaded onto the kobo collect mobile application. The data collection tools were designed with skips to reduce errors by research assistants. Prior to data collection, all research assistants received training on the study protocol and data collection. All study tools were translated into the local language and thereafter pretested. Data were collected using smart phones and tablets, and later uploaded to an online server at; https://kobo.humanitarianresponse.info. Upon submission, the data were reviewed on a daily basis by the principal investigators as a means of ensuring quality control. Prior to data analysis, data were downloaded in a Microsoft Excel format and further cleaned to reduce any possible errors. Measures of central tendency such as means, median and mode were particularly used to identify errors in the continuous variables.

Data analysis was done using STATA version 14.0. Descriptive statistics were performed to summarize both continuous and categorical variables (background characteristics of respondents, history of substance use, prevalence of hepatitis B screening and completion of the Hepatitis B vaccination schedule.

Inferential statistics were used to determine the factors associated with Hepatitis B screening, and completion of the Hepatitis B vaccination schedule. Modified Poisson regression analysis was used to determine the factors associated with Hepatitis B screening since the prevalence of screening for Hepatitis B was greater than $10 \%(34,35)$. Bivariate analysis was done first to establish the association between predictor variables and screening for Hepatitis B. A cut off $p$-value of less than 0.2 was set for variables eligible to be included in the multivariable model (36). Prevalence ratios (PR) and their corresponding $95 \%$ confidence intervals were used as the measure of risk. 
Given that the prevalence of completion of the Hepatitis B vaccination schedule was a rare occurrence (less than 10\%) among young psychoactive substance users, we used logistic regression to determine the predictors. Initially, bivariate logistic regression was used to determine the predictors of completion of the hepatitis $B$ vaccination schedule. Predictors that had a p-value of less than 0.2 were included in the multivariable model. Odds Ratios (OR) were used as the appropriate measure of risk.

\section{Results}

\section{Characteristics of respondents}

A total of 768 participants were enrolled (response rate of 100\%). The mean age (SD) of respondents were $21.5 \pm 2.1$ years. More than three quarters $(78.5 \%)$ of respondents were male, $39.2 \%$ were Catholic, $78.9 \%$ had never married, and $64.6 \%$ reported earning less than USD 68.0 per month (Table 1 ).

\section{Psychoactive substance use among young people in informal settlements}

Figure 1 shows the distribution of psychoactive substance use among respondents. About $74 \%, 54.3 \%$ and $52 \%$ were current users of alcohol, khat and marijuana respectively. In addition, $9.2 \%$ and $1.7 \%$ were current users of kuba and heroin.

\section{Hepatitis B screening and associated factors among young psychoactive substance users in Kampala's informal settlements}

Only 13.3\% reported ever being screened for HBV infection, among those 5.9\% reported to have tested positive. Two percent reported having suffered from Hepatitis B in the last 12 months (figure 2).

Table 2 shows that sex, level of education, average monthly income, knowledge about the recommended Hepatitis B vaccine doses, Hepatitis B vaccination status and attitude towards the effectiveness of Hepatitis B vaccine were significantly associated with ever screening for Hepatitis B at multivariable analysis. Females were more 1.61 times more likely to have screened for Hepatitis B compared to males (aPR 1.61, 95\% Cl: 1.11-2.33, $\mathrm{p}=0.01$ ). Young psychoactive substance users who earned more than USD 136.0 were 1.78 times more likely to have screened compared to those who earned less than USD 68.0 
(aPR 1.78, 95\% Cl: $1.11-2.86, \mathrm{p}=0.016$ ). Those unaware of the recommended vaccine doses for hepatitis B were 0.43 times less likely to have screened compared to those who knew (aPR 0.43, 95\% Cl: 0.27-0.68, $\mathrm{P}<.001)$. Those who had completed the hepatitis $\mathrm{B}$ vaccine schedule were 1.85 times more likely to have screened for hepatitis B compared to those who had not completed it (aPR 1.85, 95\% Cl: 1.26-2.70, $P=001)$. Young psychoactive substance users who believed the vaccine was effective against hepatitis $B$ were 2.34 times more likely to have screened compared to those who felt it was ineffective (APR 3.67, $95 \% \mathrm{Cl}: 2.34-5.73, \mathrm{P}<.001)$. There was no significant statistical association between age; level of education, living with parents; years of stay in the informal settlement and ever screening for hepatitis B.

\section{Hepatitis B vaccination status, knowledge and reasons for not being vaccinated.}

Only $44.4 \%$ of study participants had ever heard about hepatitis B vaccination. About $8.0 \%$ had ever received at least a dose of the hepatitis $B$ vaccine; only $2.7 \%$ had received two vaccine doses while only $2.7 \%$ had completed the hepatitis B vaccination schedule of 3 doses.

Only $8.4 \%$ of the study participants knew that the recommended vaccine dose (3 doses) for hepatitis B. Only $3.5 \%$ of the study participants knew that the vaccine can protect them against hepatitis $B$ for more than 25 years.

Figure 3 shows the reasons for not being vaccinated. $46.3 \%$ of the study participants who had never received a hepatitis $B$ vaccine dose mentioned that they were not aware of the vaccine; $28.9 \%$ did not know where to access the vaccine; $28.3 \%$ were not aware of the disease and $8.4 \%$ felt hepatitis vaccination was expensive.

\section{Factors associated with completion of the hepatitis B vaccination schedule among young psychoactive substance users in informal settlements}

Table 3 shows the factors associated with completition of the hepatitis B vaccination schedule. The level of education and knowledge about duration the vaccine was associated with hepatitis B vaccination at 
the bivariate level. At the multivariable level, knowledge about the recommended vaccine dose for hepatitis $B$, ever screening for hepatitis $B$ and the belief that the vaccine is effective in preventing hepatitis B were statistically significantly associated with completion of the vaccination schedule. The odds of completing the hepatitis $B$ vaccination schedule among young psychoactive substance users who did not know the recommended hepatitis $B$ vaccine dose were 0.06 times lower compared to those who knew the recommended vaccine dose (aOR 0.06, 95\% Cl: 0.01-0.35). The odds of completing the hepatitis $B$ vaccination schedule among young psychoactive substance users who had ever screened for hepatitis B were 9.68 times higher compared to those who had never screened (aOR 9.68, 95\% Cl: 2.1743.16, $p=0.003$ ). The odds of completing the hepatitis $B$ vaccination schedule among young psychoactive substance users who felt the vaccine was effective in preventing hepatitis $B$ were 11.8 times higher compared to those who felt it was not effective (aOR 11.8, 95\% Cl: 1.13-110.14, $p=0.039$ ).

\section{Discussion}

Among young psychoactive substance users living in urban informal settlements, we found low levels of HBV screening, HBV vaccination uptake, and low rates of completion of the vaccination schedule. These findings are significant, given the current strategy of HBV micro-elimination by 2030 (37). The strategy recommends the need to scaleup hepatitis $B$ prevention strategies to all underserved populations such as those residing in informal settlements. Screening for HBV infection is recommended for high-risk groups especially those with a prevalence of $\geq 2$ (3). However, only $13.3 \%$ of the young psychoactive substance users in this study had ever screened for hepatitis B despite a prevalence of $2.0 \%$. This is mainly attributed to the lack of awareness on HBV infection. Low awareness about HBV and its prevention has recently reported in other key populations in Uganda (38). Besides, available data indicate that informal settlements in Kampala are characterized by limited access to health care services (39), which could also have affected screening rates.

Hepatitis B screening was significantly associated with level of education, completion of the vaccination schedule and knowledge about the recommended vaccine dose. Females had 1.61 times the rate of having ever screened for hepatitis B compared to males. Females are known to have better health seeking behaviours compared to males. This could have impacted on their hepatitis $B$ screening rates. These findings are in agreement with those of Osei, Niyilapah (40) which indicated that females were more likely to screen for hepatitis $B$ compared to males. In addition, males often show a reluctancy in receiving health care services which could explain their low screening rates for hepatitis $B(41,42)$.

In some areas especially urban settings, access to screening and vaccination services comes at a cost. This study showed that young psychoactive substance users with a higher level of income were more likely to screen for hepatitis B compared to those who had a lower level of income. This could be attributed to the high cost of accessing hepatitis B prevention services (43). In some situations, health facilities providing these services are located further away from informal settlements. Therefore, young psychoactive substance users in informal settings incur transport costs to access hepatitis B prevention 
services. A lack of the financial resources therefore reduces the chances of low-income earners screening for HBV.

Completion of the hepatitis $B$ vaccination schedule was also low, due to insufficient knowledge about the vaccine and $\mathrm{HBV}$ infection, and the fact that a significant proportion of young psychoactive substance users did not know where to access the vaccine. Limited access to health services has also been documented as a barrier to uptake of hepatitis B prevention services (13). Our findings are also similar to a study among young injection drug users in the US where only $10 \%$ of younger participants reported having completed the hepatitis B vaccine series (44).

Young psychoactive substance users who had competed the hepatitis B vaccination schedule were more likely to have been screened. Usually, hepatitis B screening precedes vaccination in most healthcare facilities thus higher screening rates. Young psychoactive substance users who felt that the vaccine was effective in preventing hepatitis B viral infection were more likely to have screened for hepatitis $B$. This is so because positive attitude has been shown to positively impact the uptake of prevention services.

Lack of knowledge about the recommended vaccine dose for hepatitis B was associated with a less likelihood of completing the hepatitis B vaccination schedule. Young psychoactive substance users who were aware of the recommended vaccine dose are likely to have been sensitised about hepatitis $B$. Being knowledge about hepatitis B may have impacted on their attitude and health seeking behaviours. Consequently, these may have been motivated to take all the vaccine doses. A number of studies have concluded that an adequate level of knowledge on disease conditions increases the uptake of prevention services such as hepatitis B vaccination (40).

Young psychoactive substance users who had ever screened for hepatitis B were more likely to have completed the schedule than those who had never screened. Having screened for hepatitis B is an indicator of a better health seeking behaviour. In addition, those who had ever screened may have felt to be at an elevated risk of the HBV and therefore, undertaking the vaccination would protect them against the infection. Young psychoactive substance users who felt the vaccine was effective were more likely to have completed the vaccination schedule compared to those who did not. This re-echoes the fact that a positive attitude is more likely to positively impact preventive behaviours such as vaccination. Such individuals always believe in the protective efficacy of the vaccine, and are bound to complete the vaccination schedule at all costs.

The strength of this study is that it provides useful insights into the predictors of screening and hepatitis $B$ vaccination status of young psychoactive substance users in informal settlements, an area that is less studied. However, there are some limitations. This study relied on self-reports that may be liable to social desirability bias for substance use and testing results. The crossectional design cannot establish causation between hepatitis B screening rates and completion of the hepatitis B vaccination schedule. In addition, these results cannot be generalised to all young people living in informal settlements. 


\section{Conclusion And Recommendations}

This study indicates that both Hepatitis B screening and vaccination schedule completion rates are low among young psychoactive substance users. Generally, lack of knowledge and negative attitude towards the Hepatitis B vaccine were strong predictors of hepatitis B screening and completion of the Hepatitis B vaccination schedule. The factors associated with Hepatitis B screening among young psychoactive substance users included sex, average monthly income, knowledge about the recommended Hepatitis $B$ vaccine dose, Hepatitis $B$ vaccination completion status and attitude towards effectiveness of the Hepatitis B vaccine. The predictors of completion of the Hepatitis B vaccination schedule among young psychoactive substance users in informal settlements included knowledge about the recommended vaccine dose, having ever screened for hepatitis B and attitude towards effectiveness of Hepatitis B vaccine. The findings by this study therefore, highlight the need for the Ministry of Health to spearhead the sensitisation of young psychoactive substance users on the epidemiology of Hepatitis B. The Ministry of health should also strengthen outreach programs on Hepatitis B with keen emphasis on high-risk subgroups such as those who use psychoactive substances.

\section{Abbreviations}

HBV

Hepatitis $B$ virus

UBOS

Uganda Bureau of Statistics

WHO

World Health Organisation

\section{Declarations}

\section{Ethics approval and consent to participate}

The study protocol was approved by Makerere University School of Public Health Higher Degrees and Research Ethics Committee (MakSPH HDREC). Given the sensitivity of the study population, permission to interview the study participants was also sought from the local authorities and from peer leaders within the communities where data was collected. Written informed consent was also sought from all study participants prior to participating in the study.

\section{Consent for publication: Not applicable}

\section{Availability of data and materials}


The datasets analysed during the current study are available from the corresponding author on reasonable request.

\section{Competing interests}

The authors declare that they have no competing interests

\section{Funding}

This study was not funded by any entity

\section{Authors' contributions}

TS conceptualised the study, participated in data collection and analysis, and participated in drafting the manuscript. JBI, JNM, MT, RKM, AN, JNB, EB and SPSK participated in the analysis and drafting of the manuscript. WB and PO participated in the review of study tools, data collection and drafting the manuscript. All authors reviewed and approved the final manuscript.

\section{Acknowledgements}

We would like to thank the study community for sparing their time to participate in this study. This study would not have been a success without the help of the community guides in the study informal settlements. Your effort in connecting us to the study participants is highly appreciated. Finally, thanks go out to all our research assistants (Namulindwa Gloria, Soigi Christine, Nyakabwa Job, Andrew David Mugisha, Kiiza Ignatius and Bambuza Olivia) whose effort in undertaking the data collection is invaluable.

\section{References}

1. Merz F. United Nations Office on Drugs and Crime: World Drug Report 2017. 2017. SIRIUS-Zeitschrift für Strategische Analysen. 2018;2(1):85-6.

2. Shah DP, Grimes CZ, Nguyen AT, Lai D, Hwang L-Y. Long-term effectiveness of accelerated hepatitis $B$ vaccination schedule in drug users. Am J Public Health. 2015;105(6):e36-e43.

3. WHO. Hepatitis B 2018 [Available from: https://www.who.int/immunization/diseases/hepatitisB/en/.

4. Lamberti M, De Rosa A, Garzillo EM, Corvino AR, Sannolo N, De Pascalis S, et al. Vaccination against hepatitis b virus: are Italian medical students sufficiently protected after the public vaccination programme? Journal of Occupational Medicine and Toxicology. 2015;10(1):41. 
5. WHO. Guidelines for the Prevention Care and Treatment of Persons with Chronic Hepatitis B Infection: Mar-15: World Health Organization; 2015.

6. Lu J, Xu A, Wang J, Zhang L, Song L, Li R, et al. Direct economic burden of hepatitis B virus related diseases: evidence from Shandong, China. BMC Health Services Research. 2013;13(1):37.

7. Zhang S, Ma Q, Liang S, Xiao H, Zhuang G, Zou Y, et al. Annual economic burden of hepatitis B virusrelated diseases among hospitalized patients in twelve cities in China. Journal of Viral Hepatitis. 2016;23(3):202-10.

8. Keshavarz K, Kebriaeezadeh A, Alavian SM, Akbari Sari A, Abedin Dorkoosh F, Keshvari M, et al. Economic burden of hepatitis $B$ virus-related diseases: evidence from iran. Hepat Mon. 2015;15(4):e25854-e.

9. WHO. Guidelines on hepatitis B and C testing: policy brief. World Health Organization; 2016.

10. WHO. Hepatitis B 2019 [Available from: https://www.who.int/news-room/fact-sheets/detail/hepatitisb.

11. Bowman S, Grau LE, Singer M, Scott G, Heimer R. Factors associated with hepatitis B vaccine series completion in a randomized trial for injection drug users reached through syringe exchange programs in three US cities. BMC Public Health. 2014;14(1):820.

12. Hu Y, Grau LE, Scott G, Seal KH, Marshall PA, Singer M, et al. Economic evaluation of delivering hepatitis B vaccine to injection drug users. Am J Prev Med. 2008;35(1):25-32.

13. da Silva LN, da Silva França DD, Del-Rio NH, dos Santos Carneiro MA, Martins RM, Guimarães RA, et al. Low prevalence, low immunization and low adherence to full hepatitis $B$ vaccine scheme and high-risk behaviors among crack cocaine users in central Brazil. Journal of infection and public health. 2017;10(1):76-83.

14. Locarnini S, Hatzakis A, Chen D-S, Lok A. Strategies to control hepatitis B: Public policy, epidemiology, vaccine and drugs. Journal of Hepatology. 2015;62(1, Supplement):S76-S86.

15. Renzaho AM, Kamara JK, Georgeou N, Kamanga G. Sexual, reproductive health needs, and rights of young people in slum areas of Kampala, Uganda: a cross sectional study. PloS one. 2017;12(1):e0169721.

16. Islam MM, Gagnon AJ. Use of reproductive health care services among urban migrant women in Bangladesh. BMC women's health. 2016;16(1):15.

17. Adelson E, Nastasi BK, Maitra S, Ballal D, Rajan L. Sexual health, gender roles, and psychological well-being: Voices of female adolescents from urban slums of India. International Handbook of Psychological Well-Being in Children and Adolescents: Springer; 2016. p. 79-96.

18. van der Heijden J, Stringer B, Gray N, Kalon S, Dada M, Shaheen A, et al. The perceptions and experiences of health and health seeking behaviour for the community living in the slum areas of Kamrangirchar and Hazaribag, Dhaka, Bangladesh: a qualitative study. 2018.

19. Pryer JA. Poverty and vulnerability in Dhaka slums: the urban livelihoods study: Routledge; 2017. 
20. Richmond A, Myers I, Namuli H. Urban informality and vulnerability: A case study in Kampala, Uganda. Urban Science. 2018;2(1):22.

21. Kamath G. Hepatitis-B Vaccination, Behavioral Cognitions, and Changing Risk Behaviors among a Drug Using Population: Findings from a Cluster Randomized Controlled Trial. 2017.

22. WHO. Global health sector strategy on viral hepatitis 2016-2021. Towards ending viral hepatitis. World Health Organization; 2016.

23. Gumucio S, Luhmann N, Fauvel G, Zompi S, Ronsse A, Courcaud A, et al. The KAP survey model: Knowledge, attitude, and practices. Saint-Etienne, France: IGC Communigraphie. 2011:4-5.

24. Du Monde M. The KAP Survey Model (Knowledge, Attitudes, and Practices). 2011. 2016.

25. Liu Y, Ma C, Jia H, Xu E, Zhou Y, Zhang Z, et al. Knowledge, attitudes, and practices regarding hepatitis $B$ vaccination among hospital-based doctors and nurses in China: Results of a multi-site survey. Vaccine. 2018;36(17):2307-13.

26. Saquib S, Ibrahim W, Othman A, Assiri M, Al-Shari H, Al-Qarni A. Exploring the Knowledge, Attitude and Practice Regarding Hepatitis B Infection Among Dental Students in Saudi Arabia: A CrossSectional Study. Open Access Maced J Med Sci. 2019;7(5):805-9.

27. Shindano T, Bahizire E, Fiasse R, Horsmans Y. Knowledge, Attitudes, and Practices of Health-Care Workers About Viral Hepatitis B and C in South Kivu. American Journal of Tropical Medicine and Hygiene. 2016;96.

28. UBOS. The National Population and Housing Census 2014 - Area Specific Profile Series, Kampala, Uganda. Kampala: Uganda Bureau of Statistics 2017.

29. Kish L. Survey Sampling, New York: Wiley. ISBN 978-0471109495. 1965.

30. Martínez-Mesa J, González-Chica DA, Bastos JL, Bonamigo RR, Duquia RP. Sample size: how many participants do I need in my research? Anais brasileiros de dermatologia. 2014;89(4):609-15.

31. WHO, CDC, UNAIDS, FHI360. Biobehavioral survey guidelines for Populations at Risk for HIV. Geneva: World Health Organization. Geneva: WHO Press, World Health Organization; 2017.

32. Ssekamatte T, Isunju JB, Balugaba BE, Nakirya D, Osuret J, Mguni P, et al. Opportunities and barriers to effective operation and maintenance of public toilets in informal settlements: perspectives from toilet operators in Kampala. International Journal of Environmental Health Research. 2019;29(4):35970 .

33. WHO. Hepatitis B vaccines: WHO position paper-Recommendations. Vaccine. 2010;28(3):589-90.

34. Zou G. A modified poisson regression approach to prospective studies with binary data. American journal of epidemiology. 2004;159(7):702-6.

35. Zou G, Donner A. Extension of the modified Poisson regression model to prospective studies with correlated binary data. Statistical methods in medical research. 2013;22(6):661-70.

36. Bursac Z, Gauss CH, Williams DK, Hosmer DW. Purposeful selection of variables in logistic regression. Source code for biology and medicine. 2008;3(1):17. 
37. WHO. Combating hepatitis B and C to reach elimination by 2030: advocacy brief. World Health Organization; 2016.

38. Nankya-Mutyoba J, Aizire J, Makumbi F, Atuyambe L, Ocama P, Kirk GD. Correlates of hepatitis B awareness and disease-specific knowledge among pregnant women in Northern and Central Uganda: a cross-sectional study. Hepatology, Medicine and Policy. 2018;3(1):14.

39. Renzaho AMN, Kamara JK, Georgeou N, Kamanga G. Sexual, Reproductive Health Needs, and Rights of Young People in Slum Areas of Kampala, Uganda: A Cross Sectional Study. PLOS ONE. 2017;12(1):e0169721.

40. Osei E, Niyilapah J, Kofi Amenuvegbe G. Hepatitis B Knowledge, Testing, and Vaccination History among Undergraduate Public Health Students in Ghana. BioMed research international. 2019;2019.

41. Ek S. Gender differences in health information behaviour: a Finnish population-based survey. Health promotion international. 2013;30(3):736-45.

42. Hunt K, Adamson J, Hewitt C, Nazareth I. Do women consult more than men? A review of gender and consultation for back pain and headache. Journal of health services research \& policy. 2011;16(2):108-17.

43. Wibabara Y, Banura C, Kalyango J, Karamagi C, Kityamuwesi A, Amia WC, et al. Hepatitis B vaccination status and associated factors among undergraduate students of Makerere University College of Health Sciences. PloS one. 2019;14(4):e0214732.

44. Seal KH, Edlin BR, Ochoa KC, Tulsky JP, Moss AR, Hahn JA. Risk of hepatitis B infection among young injection drug users in San Francisco: opportunities for intervention. Western Journal of Medicine. 2000;172(1):16.

\section{Tables}

Table 1. Background characteristics of respondents 


\begin{tabular}{|c|c|c|c|}
\hline Characteristic & Category & Frequency $(n=768)$ & Percentage (\%) \\
\hline \multirow{2}{*}{$\begin{array}{l}\text { Age } \\
\text { Mean }(\mathrm{SD})=21.5 \pm 2.1)\end{array}$} & $18-19$ & 190 & 24.7 \\
\hline & $20-24$ & 578 & 75.3 \\
\hline \multirow[t]{2}{*}{ Sex } & Male & 603 & 78.5 \\
\hline & Female & 165 & 21.5 \\
\hline \multirow[t]{2}{*}{ Marital status } & Never married & 606 & 78.9 \\
\hline & Married & 162 & 21.1 \\
\hline \multirow[t]{5}{*}{ Religion } & Catholic & 301 & 39.2 \\
\hline & Anglican & 128 & 16.7 \\
\hline & Muslim & 231 & 30.1 \\
\hline & Born again/ Pentecostal & 83 & 10.8 \\
\hline & Other religions & 25 & 3.3 \\
\hline \multirow[t]{2}{*}{ Level of education } & Primary & 322 & 41.9 \\
\hline & Secondary and above & 446 & 58.1 \\
\hline \multirow[t]{3}{*}{ Years of staying in area } & $0-5$ years & 279 & 36.3 \\
\hline & $6-10$ years & 149 & 19.4 \\
\hline & $>10$ years & 340 & 44.3 \\
\hline \multirow{3}{*}{$\begin{array}{l}\text { Average monthly income (in USD) } \\
\text { Exchange rate ( } 1 \text { USD=UGX 3676) }\end{array}$} & $\leq 68.0$ & 496 & 64.6 \\
\hline & 68.1-136 & 207 & 27.0 \\
\hline & Above 136 & 65 & 8.5 \\
\hline
\end{tabular}

Table 2: Factors associated with "ever screening for hepatitis B" among young psychoactive substance users 


\begin{tabular}{|c|c|c|c|c|c|c|c|}
\hline & \multirow{2}{*}{$\begin{array}{l}\text { Freq } \\
\text { (n) }\end{array}$} & \multicolumn{2}{|c|}{ Ever screened for hepatitis B } & \multirow[t]{2}{*}{ CPR $(95 \%$ CI) } & \multirow[t]{2}{*}{$P$ value } & \multirow[t]{2}{*}{ aPR $(95 \% \mathrm{CI})$} & \multirow[t]{2}{*}{ P-value } \\
\hline & & Yes & No & & & & \\
\hline & 603 & $69(67.6)$ & $534(80.2)$ & 1 & & & \\
\hline & 165 & $33(32.4)$ & $132(19.8)$ & $1.74(1.19-2.54)$ & 0.004 & $1.61(1.11-2.33)$ & $0.010^{*}$ \\
\hline \multicolumn{8}{|l|}{ gory } \\
\hline & 190 & $23(22.5)$ & $167(25.1)$ & 1 & & & \\
\hline & 578 & 79 (77.5) & 499 (74.9) & $1.12(0.73-1.74)$ & 0.584 & $1.01(0.67-1.52)$ & 0.952 \\
\hline \multicolumn{8}{|l|}{ əducation } \\
\hline & 322 & $24(23.5)$ & $298(44.7)$ & 1 & & & \\
\hline imary & 446 & 78 (76.6) & $368(55.3)$ & $2.34(1.51-3.62)$ & $\mathrm{P}<.001$ & $1.49(0.99-2.26)$ & 0.055 \\
\hline \multicolumn{8}{|l|}{ tatus } \\
\hline & 606 & 77 (75.5) & $529(79.4)$ & 1 & & & \\
\hline & 162 & $25(24.5)$ & $137(20.6)$ & $1.21(0.80-1.84)$ & 0.361 & & \\
\hline \multicolumn{8}{|c|}{ g with parents } \\
\hline & 120 & $18(17.6)$ & $102(15.3)$ & 1 & & & \\
\hline & 648 & $84(82.4)$ & $564(84.7)$ & $0.86(0.53-1.38)$ & 0.543 & & \\
\hline \multicolumn{8}{|c|}{ monthly income (USD) } \\
\hline & 496 & $60(58.8)$ & $436(65.4)$ & 1 & & & \\
\hline & 207 & $26(25.5)$ & $181(27.2)$ & $1.03(0.67-1.59)$ & 0.864 & $1.18(0.79-1.76)$ & 0.411 \\
\hline 6 & 65 & $16(15.7)$ & $49(7.4)$ & $2.03(1.24-3.31)$ & 0.004 & $1.78(1.11-2.86)$ & $0.016^{*}$ \\
\hline \multicolumn{8}{|c|}{ stay in informal settlement } \\
\hline ; & 279 & $39(38.2)$ & $240(36.1)$ & 1 & & & \\
\hline rs & 149 & $17(16.7)$ & $132(19.8)$ & $0.81(0.47-1.39)$ & 0.456 & & \\
\hline n 10 years & 340 & $46(45.1)$ & $294(44.1)$ & $0.96(0.65-1.43)$ & 0.872 & & \\
\hline \multicolumn{8}{|c|}{ recommended HB vaccine dose } \\
\hline & 65 & $38(37.2)$ & $27(4.1)$ & 1 & & & \\
\hline & 703 & $64(62.8)$ & 639 (95.9) & $0.15(0.11-0.21)$ & $\mathrm{P}<.001$ & $0.43(0.27-0.68)$ & $<.001 *$ \\
\hline \multicolumn{8}{|c|}{ duration the vaccine provides protection against HBV } \\
\hline & 741 & $89(87.3)$ & $652(97.9)$ & 1 & & & \\
\hline & 27 & $13(12.7)$ & $14(2.1)$ & $4.00(2.58-6.20)$ & $\mathrm{P}<.001$ & $0.78(0.47-1.31)$ & 0.362 \\
\hline \multicolumn{8}{|c|}{ B vaccination completion status } \\
\hline te & 747 & $84(82.3)$ & $663(99.6)$ & 1 & & & \\
\hline d & 21 & $18(17.7)$ & $3(0.4)$ & $7.62(5.83-9.95)$ & $\mathrm{P}<.001$ & $1.85(1.26-2.70)$ & $0.001 *$ \\
\hline \multicolumn{8}{|c|}{ :owards effectiveness of Hep B vaccine } \\
\hline ffective & 587 & $35(34.3)$ & $552(82.9)$ & 1 & & & \\
\hline :tive & 181 & $67(65.7)$ & $114(17.1)$ & $6.20(4.27-9.01)$ & $\mathrm{P}<.001$ & 3.67 (2.34-5.73) & $<.001 *$ \\
\hline
\end{tabular}

* Considering a 95\% CI, a p-value $\leq 0.05$ was considered to be statistically significant in this study.

$C P R=$ Crude Prevalence Ratio, $A P R=$ Adjusted Prevalence Ratio

Table 3: Predictors of hepatitis B vaccination status among young psychoactive substance users in Kampala, Uganda 


\begin{tabular}{|c|c|c|c|c|c|c|c|}
\hline & \multirow{2}{*}{$\begin{array}{l}\text { Freq } \\
\text { (n) }\end{array}$} & \multicolumn{2}{|c|}{ Vaccination status } & \multirow[b]{2}{*}{ COR $(95 \% \mathrm{CI})$} & \multirow[t]{2}{*}{$P$ value } & \multirow[t]{2}{*}{ AOR (95\% CI) } & \multirow[t]{2}{*}{$P$ value } \\
\hline & & Completed & Incomplete & & & & \\
\hline \multicolumn{8}{|c|}{ e respondents } \\
\hline & 603 & $13(61.9)$ & $590(79.0)$ & 1 & & & \\
\hline & 165 & $8(38.1)$ & $157(21.0)$ & $2.31(0.94-5.67)$ & 0.067 & $1.92(0.50-7.35)$ & 0.337 \\
\hline \multicolumn{8}{|l|}{ jory } \\
\hline & 190 & $3(14.3)$ & $187(25.0)$ & 1 & & & \\
\hline & 578 & $18(85.7)$ & $560(75.0)$ & $2.00(0.58-6.87)$ & 0.269 & $1.25(0.23-6.63)$ & 0.793 \\
\hline \multicolumn{8}{|l|}{ education } \\
\hline & 322 & $4(19.0)$ & 318 (42.6) & 1 & & & \\
\hline imary & 446 & $17(81.0)$ & $429(57.4)$ & $3.15(1.04-9.45)$ & 0.041 & $0.55(0.10-2.80)$ & 0.474 \\
\hline \multicolumn{8}{|l|}{ tatus } \\
\hline & 606 & $14(66.7)$ & $592(79.3)$ & 1 & & & \\
\hline & 162 & 7 (33.3) & 155 (20.7) & $1.90(0.75-4.81)$ & 0.17 & $2.49(0.55-11.16)$ & 0.231 \\
\hline \multicolumn{8}{|c|}{ rangements } \\
\hline parents & 120 & $2(9.5)$ & $118(15.8)$ & 1 & & & \\
\hline ent & 648 & 19 990.5) & $629(84.2)$ & $1.78(0.40-7.75)$ & 0.441 & & \\
\hline \multicolumn{8}{|c|}{ monthly income } \\
\hline & 496 & $17(81.0)$ & $479(64.1)$ & 1 & & & \\
\hline & 207 & $2(9.5)$ & 205 (27.4) & $2.74(0.62-1.20)$ & 0.086 & $0.22(0.03-1.43)$ & 0.114 \\
\hline 6 & 65 & $2(9.5)$ & $63(8.4)$ & $0.89(0.20-3.96)$ & 0.883 & $0.50(0.07-3.37)$ & 0.479 \\
\hline \multicolumn{8}{|c|}{ of stay in the informal settlement } \\
\hline ; & 279 & $9(42.9)$ & $270(36.1)$ & 1 & & & \\
\hline rs & 149 & $5(23.8)$ & $144(19.3)$ & $1.04(0.34-3.16)$ & 0.943 & & \\
\hline n 10 years & 340 & $7(33.3)$ & $333(44.6)$ & $0.63(0.23-1.71)$ & 0.367 & & \\
\hline \multicolumn{8}{|c|}{ recommended vaccine dose } \\
\hline & 65 & 19 (90.5) & $46(6.2)$ & 1 & & & \\
\hline & 703 & $2(9.5)$ & $701(93.8)$ & $0.01(0.01-0.03)$ & $\mathrm{P}<.001$ & $0.06(0.01-0.35)$ & $0.002 *$ \\
\hline \multicolumn{8}{|c|}{ duration the vaccine provides protection } \\
\hline & 741 & $12(57.1)$ & $729(97.6)$ & 1 & & & \\
\hline & 27 & $9(42.9)$ & $18(2.4)$ & $30.37(11.36-81.14)$ & $\mathrm{P}<.001$ & $3.62(0.79-16.60)$ & 0.098 \\
\hline \multicolumn{8}{|c|}{ sened for hepatitis B } \\
\hline & 666 & $3(14.3)$ & $663(88.3)$ & 1 & & & \\
\hline & 102 & $18(85.7)$ & $84(11.2)$ & $47.3(13.66-164.16)$ & $\mathrm{P}<.001$ & $9.68(2.17-43.16)$ & $0.003^{*}$ \\
\hline \multicolumn{8}{|c|}{ :owards effectiveness of Hep B vaccine } \\
\hline \multirow[t]{2}{*}{ tive } & 587 & $1(4.8)$ & 586 (78.5) & 1 & & 1 & \\
\hline & 181 & $20(95.2)$ & 161 (21.5) & $72.7(9.69-546.52)$ & $\mathrm{P}<.001$ & $11.8(1.13-110.14)$ & $0.039 *$ \\
\hline
\end{tabular}

Considering a 95\% CI, a p-value $\leq 0.05^{*}$ was considered to be statistically significant in this study. COR =Crude Odds Ratio, AOR=Adjusted Odds Ratio

\section{Figures}




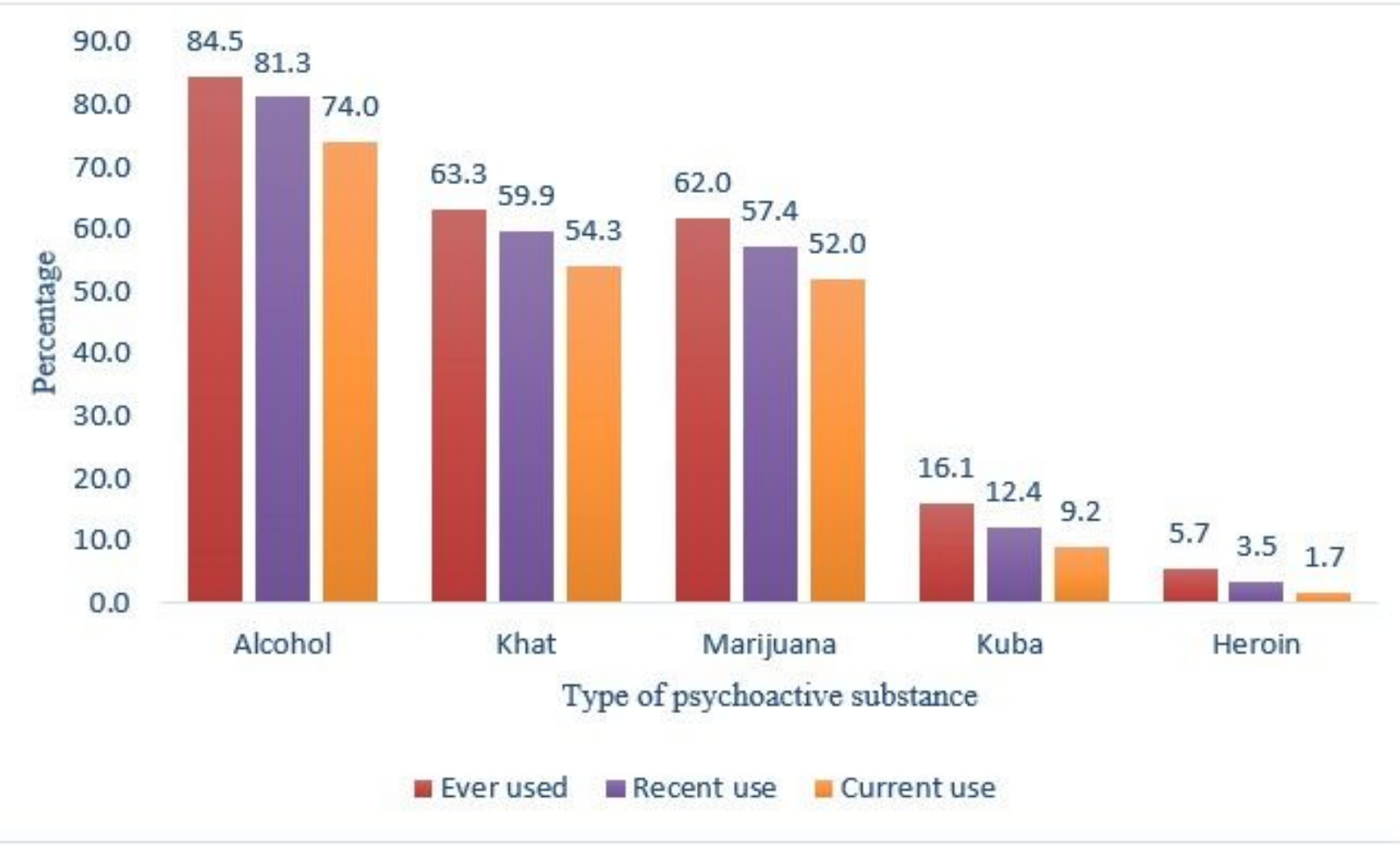

\section{Figure 1}

History of psychoactive substance use among young people in Kampala's informal settlements

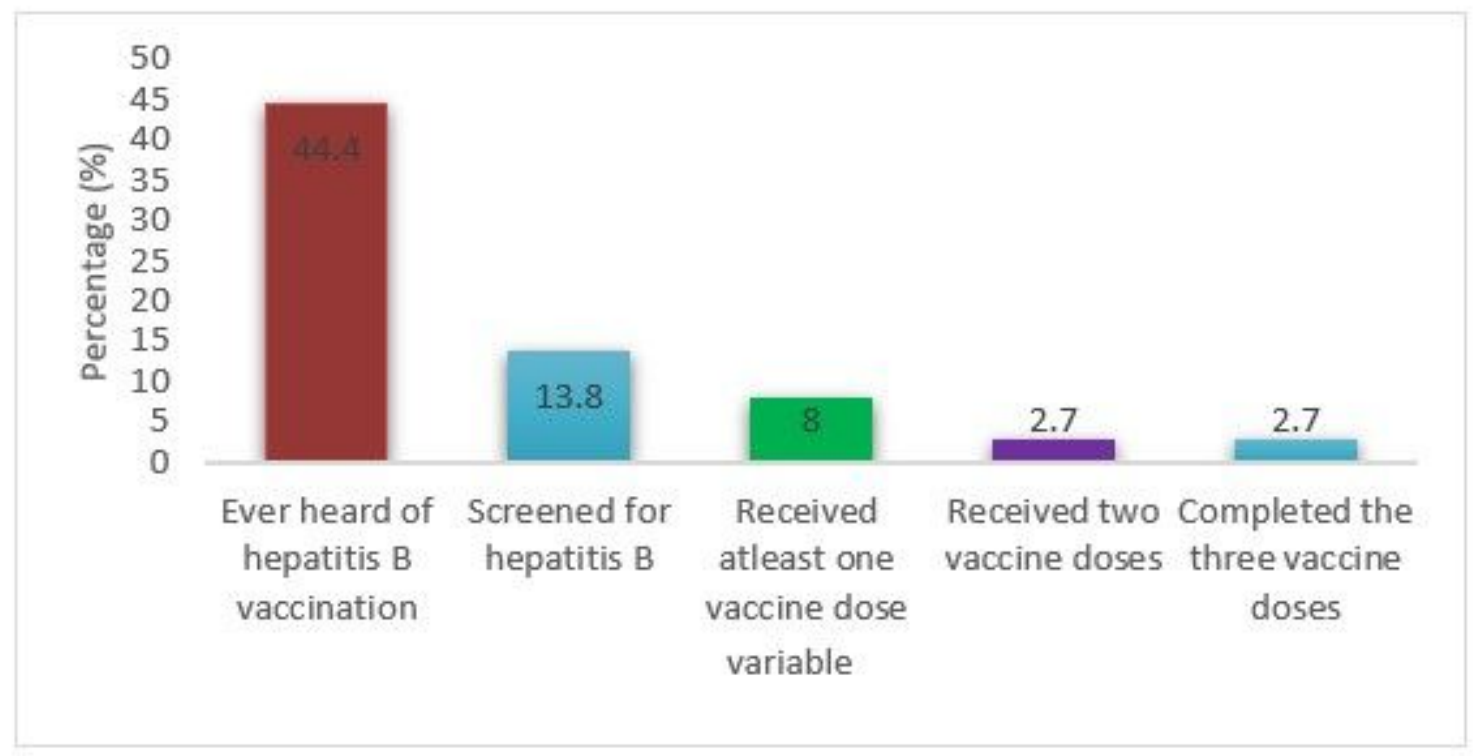

Figure 2

Hepatitis B testing and vaccination among young psychoactive substance users in Kampala's informal settlements 


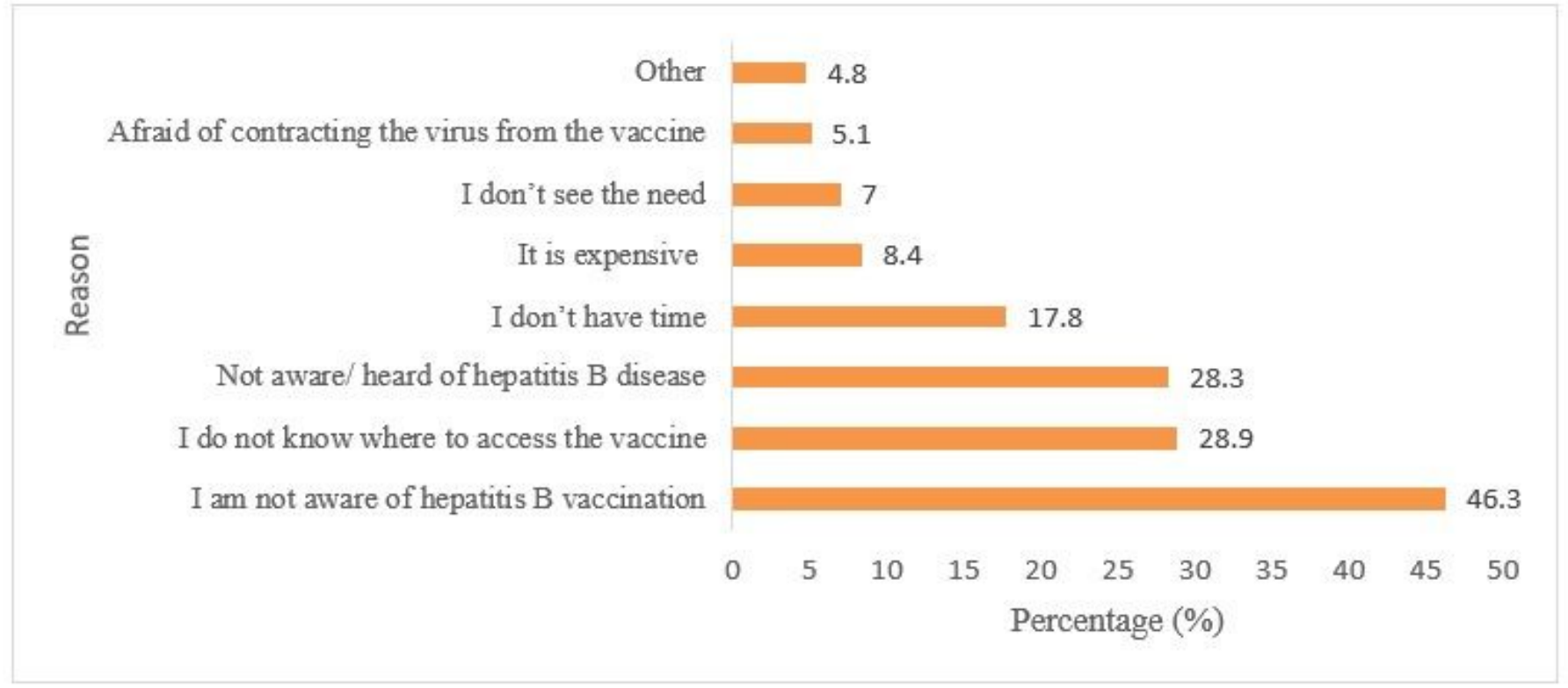

\section{Figure 3}

Reasons young psychoactive substance users gave for not being vaccinated against hepatitis B (Multiple responses) 